\title{
Incorporación de tecnología médica en nuestro país: Reflexiones de cómo hacerlo
}

La educación global exige buscar vías para cambiar el mundo cuando este no reúne óptimos estándares, cuando los recursos están injustamente distribuidos, cuando los conflictos derivan en violencia, y cuando los derechos humanos son transgredidos.

La tecnología está guiada por una misión, que promueve un compromiso común hacía el mundo y las personas. Promue ve el respeto, la tolerancia y la justicia. A ctualmente vivimos un darwinismo global que, en treinta años, duplicará el número de pobres del mundo. Es decir, se globalizará la pobreza. Para una mejor distribución del ingreso mundial en beneficio de pobres y ricos, se debe volver a admitir que los problemas globales tienen soluciones locales y que no hay global ización sin una sociedad sana.

A lgunas cifras son alarmantes y reclaman solución. En el hemisferio Norte el $20 \%$ de la humanidad recibe el $80 \%$ del ingreso mundial, mientras en el Sur, dos mil millones de humanos viven en pobreza extrema, con ingresos de noventa dólares al mes. Hay mil millones de iletrados en el mundo, la gran mayoría sin servicios de salud, y así no pueden generar riqueza.

Sin medios de producir ni distribuir la riqueza y con la exigencia de abrir mercados a los países desarrollados, so pretexto de la globalización, mientras ellos ponen restricciones a las importaciones y dan subsidios a sus productores. EI avance tecnológico y científico nos obliga a adquirir tecnología moderna para incorporar a los sistemas de organización de todos los países del mundo.

La tecnología se une al mercado, a la industria médica, a los programas de mercadeo, exhibiciones, regalos, promociones etc, en donde poco se valoran los hechos importantes de la tecnología científica. A veces se ve al médico y cirujano como socio de la industria.

La ética de aplicar nueva tecnología debe fundamentarse sólidamente.

La evaluación de estudios clínicos debe tener el consentimiento informado (autonomía), el factor beneficencia (beneficio al participante) y la llamada nonmalfeasance (no dañar al participante).

Las nuevas tecnologías pueden interponer barreras entre paciente y médico, pues la especialización y subespecial ización de profesionales los limita muchas veces a ver sus pacientes como solo una parte u órgano, no con una visión general, humana, holística de su sujeto. La telecirugía y robótica, el soporte vital con tecnología avanzada, ponen también a prueba, en su límite este campo.

Según el Dr. Morgernstern, profesor Emérito de UCLA, la base de la ética profesional es la competencia; la mejor atención se hace de la manera más competente; nuevas técnicas deben ser aprendidas, practicadas y dominadas antes de ejecutarse; en gran parte, la competencia depende del equipo, asistentes y servicio de apoyo.

Los principios básicos en tecnologías quirúrgicas emergentes propuestos por el Colegio A mericano de Cirujanos, se basan en tres postulados:

- Su desarrollo deber ser acompañado de una evaluación científica de su seguridad, eficacia general y necesidad.

- Su difusión clínica requiere educación y evaluación apropiada de los cirujanos. Un requisito es el conocimiento de la enfermedad por tratar, la adquisición de las destrezas técnicas y facilidades de respaldo sujeta a control periódico de los resultados.

- Su aplicación generalizada debe evaluarse continuamente y compararse con terapias alternas para asegurar idoneidad y costo efectividad, por medio de estudios de los resultados.

La tecnología médica en el diagnostico también debe ser fundamentada.

La gama de equipos técnicos y medios auxiliares de la medicina que tiene fines diagnósticos en consultorios médicos, laboratorios y hospitales, abarca desde la simple espátula de madera para ver la faringe, hasta los emisores de positrones por ordenador. Incluye técnicas para vigilancia, monitoreo y diagnóstico vital de valores circulatorios, respiratorios, cerebrales, en cuidados intensivos, sala de operaciones, incubadoras, en forma sistemática o aislada específica. También contempla máquinas para registro cardiorespiratorio, el ectroencefalógrafo por ordenador, espirómetros, radiodiagnóstico de todo tipo (radiografía digital), angiografía por sustracción, tomografía por ordenador, por resonancia magnética, diagnóstico nuclear, por ultrasonido, endoscopía, oftalmológicas, equipos biológicos y de análisis químico, microscopía, etc. 
La tecnología médica en la terapia también es variada y compleja. Sus principios físicos son los mismos de la diagnóstica. M uchas veces su impacto es mayor, como en el caso de la radioterapia con cobal to, acelerador lineal, litotripcia, odontología, por corrientes estimulantes, ultrasonido, termoterapia, diálisis, microcirugía, láser, equipos de anestesia y respiración artificial, corazón y pulmón artificial.

Los equipos técnicos de la medicina se caracterizan por un elevado potencial de riesgo siniestral, ya que se encuentran en espacios pequeños, con alta sensibilidad de la microelectrónica y de la medicina de precisión, frente a influencias externas. Su mantenimiento regular es imprescindible para garantizar su óptima operación por lo que se debe tener un contrato de mantenimiento y un seguro de bienes siniestrales.
Los médicos líderes en su campo, quienes son los responsables de comprar, asesorar, usar, desestimar y hacer clara una mala función, deben actuar con transparencia de acuerdo con principios y normas, de manera que su procedimiento sea visible para todos; es preciso que sean concordantes entre lo que dicen y hacen, tengan ideas claras, fundamentadas, expresadas con lucidez y coherencia, y con poder de operativización.

Todo lo anterior tiene el propósito de que estas ideas aporten soluciones a la gran discusión y problemática de la tecnología, ante el atraso tecnológico y la necesidad de incorporarlas perentoriamente en nuestros países.

\section{Dr. Eduardo Flores Montero Presidente \\ Colegio de Médicos y Cirujanos de Costa Rica}

